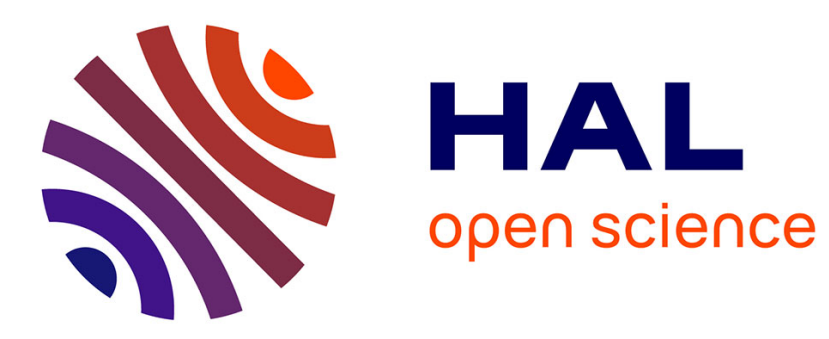

\title{
"The Same Thing in a Different Box": Similarity and Difference in Pharmaceutical Sex Hormone Consumption and Marketing
}

Emilia Sanabria

\section{- To cite this version:}

Emilia Sanabria. "The Same Thing in a Different Box": Similarity and Difference in Pharmaceutical Sex Hormone Consumption and Marketing. Medical Anthropology Quarterly, 2014, 28 (4), pp.537555. 10.1111/maq.12123 . halshs-01059028

\section{HAL Id: halshs-01059028 \\ https://shs.hal.science/halshs-01059028}

Submitted on 29 Aug 2014

HAL is a multi-disciplinary open access archive for the deposit and dissemination of scientific research documents, whether they are published or not. The documents may come from teaching and research institutions in France or abroad, or from public or private research centers.
L'archive ouverte pluridisciplinaire $\mathbf{H A L}$, est destinée au dépôt et à la diffusion de documents scientifiques de niveau recherche, publiés ou non, émanant des établissements d'enseignement et de recherche français ou étrangers, des laboratoires publics ou privés. 


\section{Medical Anthropology Quarterly \\ International Journal for the Analysis of Health | Society for Medical Anthropology}

Title: "The Same Thing in a Different Box": Similarity and Difference in Pharmaceutical Sex Hormone Consumption and Marketing

Author: Emilia Sanabria

Medical Anthropology Quarterly; 2014.

This is the author's post-print. Please cite the final version of the article, available at http://dx.doi.org/10.1111/maq.12123.

Medical Anthropology Quarterly is collaborating with the University of Florida Libraries to digitize, preserve, and extend access to the journal's content. The Digital Library Center (DLC) at the University of Florida is a nonprofit center responsible for the collection and preservation of digital resources for education. For more information about DLC, please contact DLC@uflib.ufl.edu.

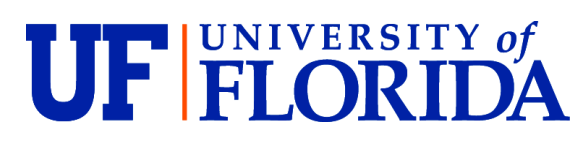




\section{Emilia Sanabria}

Ecole normale supérieure de Lyon

Laboratoire Triangle \& INSERM, France

(E-mail: emilia.sanabria@ens-lyon.fr)

\section{"The Same Thing in a Different Box": Similarity and Difference in Pharmaceutical Sex Hormone Consumption and Marketing}

The contraceptive pill has given way to a multitude of products, packaging, and modes of administration. This article draws on work on the pharmaceutical copy, extending the analysis to differentiating between forms of administration for contraceptive medicines as well as between brand-name drugs, generics, and similares, as they are known in Brazil. It explores how Brazilian prescribers and users-within the divergent structural constraints afforded by private and public health-apprehend and negotiate distinctions between the drugs available to them. This ethnographic account of hormone use reveals new fault lines through which the pharmakon exerts it influence. The attention that industry places on pharmacodynamics as it produces new products from similar compounds suggests that pharmaceutical effects are at once symbolic and real. The article concludes with a reflection on the future of the generic form in a field increasingly crowded by branded copies. [contraception, pharmaceuticals, generics, the pill, Brazil]

\section{Introduction}

The oral contraceptive pill has become a fairly ubiquitous object. So much so that it is known as the pill. Yet, behind the apparent unity of this object lies what Mol (2002) would call "multiplicity." This article examines what gives this medical object its unity and analyzes the social and regulatory practices that are at work in the making or unmaking of this unity. My concern with how synthetic sex hormones are produced as contraceptives stems from an ethnographic conundrum. In studying the impact of the pill on women's contraceptive practices, one is faced with an array of different objects, often lumped together as one. How can a thing like the pill be one and many simultaneously? Why does this object vary so widely? How can we account for its concurrent lability and condition as a tangible, material object?

Since its inception in the early 1960s, the pill has given way to a multitude of products, in different forms of packaging and modes of administration. First, there is a profusion of orally administered pills: combination pills (estrogen and progesterone), mini-pills, extendedregime pills, or emergency pills, combining any variation of the plethora of synthetically produced hormones. These can, in turn, be brand-name drugs produced by international pharmaceutical laboratories or copies of these. This article is based on ethnographic research in Brazil, where a dynamic pharmaceutical industry specializes in copying what are locally referred to as medicamentos de marca (brand-name medicines) (Cassier and Corrêa 2009). Only a small percentage of these copies are registered as "generics" by the Brazilian Agency of Sanitary Vigilance (ANVISA) in charge of pharmacovigilance.

The majority of copies currently available in Brazil are classified as similares (literally, similar drugs) — not generics — and it is widely estimated that these represent $65 \%$ of the total Brazilian pharmaceutical market. In addition to this profusion of oral forms, contraceptive sex hormones may be injected, implanted subdermally, absorbed through the skin (via transdermal patches or gels), the vagina (via a vaginal ring) or the uterus (via an 
intra-uterine hormone-releasing system). The making of this multiplicity relates to the search for long-acting contraceptive methods for the so-called developing world in which Brazilian medical institutions played a significant role.

This article explores the dynamic between similarity and difference in pharmaceutical sex hormone marketing and prescription strategies in Brazil. This dynamic hinges on a process of multiplying different consumer populations within complex and shifting biopolitical rationalities of reproduction (Krause and De Zordo 2012; Sanabria 2010a). In the late 1980s, Brazil underwent a period of democratic reform in which the "universal" public health system known as the Sistema Único de Saúde (SUS) was consolidated. The SUS coexists with a dynamic system of private health to which $20-25 \%$ of the Brazilian population subscribes. ${ }^{1}$ Many private health institutions provide services for the SUS, sometimes offering a dual standard of care.

Health disparities within Brazil are further compounded by important regional variations in access to services. Access to contraception in Brazil is highly stratified, revealing profound socioeconomic disparities, notably in its reliance on surgical sterilization. Although rates of sterilization declined from $38.5 \%$ of contraceptive use in 1996 to $25 \%$ in 2006, significant disparities emerge when analyzing these figures according to level of education or economic class. ${ }^{2}$ Non-oral hormonal methods, such as contraceptive injections, hormonal implants, or intra-uterine hormonal devices like Mirena, are specifically pitched by health providers as alternatives to sterilization - the rates of which remain uncharacteristically high.

Pharmacies remain the principle source for hormonal contraceptives, particularly for those groups at either end of the social spectrum. To understand the dynamics around hormonal contraception use, one therefore needs to look beyond the activities in the public health sector and to pay attention to the prescription practices in the private sector and to what take place across the counter, in pharmacies. This is a blind spot in much of the literature on contraception in Brazil, which, in focusing on women's perceptions or the problem of unmet contraceptive needs, overlooks the way contraceptive decision-making is also shaped by feedbacks between pharmaceutical promotional strategies and prescription practices or by the dynamics of "switching" that take place within pharmacies.

\section{Methods and Setting: Tracking Pharmaceuticals in Salvador da Bahia}

The ethnographic materials presented here were gathered in Salvador, capital of the northeastern state of Bahia, as part of a research project on menstruation, contraception, and sexual and reproductive health practices. This involved 18 months of fieldwork (in 2005-6) during which I attended over 300 family-planning consultations across three distinct public sector services and in several private practices. ${ }^{3}$ I also conducted over 70 in-depth interviews with women across all classes.

During this period and in four subsequent visits of three to six months between 2008 and 2013, I attended three medical congresses and interviewed doctors, nurses, and health planners. The repackaging of hormonal contraceptives rapidly emerged as an important methodological concern, so I embarked on ethnographic work in the pharmaceutical sector. I carried out several weeks of fieldwork in three pharmacies catering to low-, middle-, and high-income neighborhoods and met pharmacy sector regulators and members of pharmacist professional organizations. I interviewed the national marketing directors of four major pharmaceutical corporations in São Paulo (Schering, Pfizer, Libbs, and Boehringer Ingelheim) and followed the work of Schering's, Libbs's, and Organon's regional managers over the course of several months. I met a number of other pharmaceutical representatives in doctors' waiting-rooms, some of whom allowed me to observe their work. ${ }^{4}$ Through these 
contacts, I was invited to several pharmaceutical promotion events (such as conference dinners and congresses).

Although $90 \%$ of drugs are bought out of pocket (Thuot et al. 2012), Brazil is one of the largest consumers of pharmaceutical drugs and the seventh-largest market worldwide. A cardiologist cited by Petryna (2009:145) attributes Brazil's "voracious pharmaceutical demand" to aggressive marketing, lack of enforced state regulation, and a bias for brandname drugs. Growth in the pharmaceutical sector is estimated at $13 \%$, partly due to a booming industry of generic copies. This places Brazil among the high-growth nations referred to as "pharmerging." Pharmerging markets are characterized by the Institute for Healthcare Informatics by a rapid increase in drug consumption, with a shift in spending away from branded products toward generics (IMS 2011). These shifts are imputed to a synchrony between historically high levels of patent expirations and improved economic conditions driving demand for drugs, particularly generics (IMS 2011:3). This points to tremendous tensions between brands and copies in global pharmaceutical markets.

The concept of pharmerging sheds light on how national development, democratization through the extension of citizenship to the global poor and pharmaceutical consumption are imbricated in conceptualizations of the role of pharmaceuticals in global development. In this article, I examine some implications the dynamics of pharmerging markets has on the way drugs are perceived and used in Brazil. I explore how Brazilian prescribers and users - within the divergent structural constraints afforded by private and public health - apprehend distinctions between brand-name contraceptives, their copies, and their different modes of administration. For this reason, I trace the differences among what is commonly presented as similar and the similarities that insinuate themselves in things presented as different. This attention to the interplay between similarity and difference takes its inspiration in the work of Hayden $(2007,2010)$ on the pharmaceutical copy, extending the analysis to the work of making difference and similarity between forms of administration for hormonal contraceptive methods.

\section{Interchangeability: How Different Things Are Made Similar}

Throughout the 1960-70s, and under the military dictatorship of Getúlio Vargas, the Brazilian state adopted an explicitly pronatalist stance. The absence of a national familyplanning strategy created a void. Corrêa (2001:56) argues that the "medicalization of reproduction" in Brazil was led by private sector initiatives, often contrary to the official state position. This resulted in a contraceptive praxis characterized by drugstore-promoted selfmedication that gradually leads women to turn to sterilization. Mapping the history of the pill's uptake in Brazil is difficult because it was not introduced as part of a planned public policy (Loyola 2010; Pedro 2003). Enovid, the first pill to be introduced in Brazil, was promoted by salespersons in private gynecological practices and available in pharmacies, although its cost was prohibitive for most (Pedro 2003). The pill was unevenly diffused among low-income women by the interventions of international non-governmental organizations. The first state program to include family planning was launched in 1977. In her oral history of the pill in Brazil, Pedro (2003) found that women recollected experiencing many discomforts with the pill, a fact mirrored in the media coverage that emphasized, from the outset, the risks and side effects of the initially highly dosed pills.

Contraceptive choice is a foundational aspect of reproductive and sexual rights. Hartman (1995) argues that population control programs impose birth control from above, limiting choice of methods. Against this, she pitches reproductive health programs that offer a wide range of methods and access to safe abortion (Hartman 1995:57). The distinction is more heuristic than descriptive, as elements of both ideal types exist in the day-to-day 
practices of reproductive health services worldwide. However, it illustrates the rhetorical importance of contraceptive method diversity in reproductive health. My aim is to highlight the ways in which this contributes to constructing a form of interchangeability between contraceptive methods and between hormonal methods in particular. This permutability between methods opens up the first notion of similarity between medicines that I would like to highlight. The logic of choice that permeates these contexts implies that women select from a range of similar options. In the context of promoting choice, differences between methods are temporarily bracketed, as an emphasis is placed on finding the most suitable method among what is essentially foregrounded as equivalent choices.

In Bahian public ambulatórios (out-patient clinics), it is common for choice to be limited by a lack of methods. The methods available in the family-planning units I researched tended to include one or two types of oral contraceptive pills, hormonal injections, and copper intra-uterine devices. In these contexts, where the average consultation with the doctor is seldom longer than five minutes, women who express difficulties with a particular pill or want to change methods are given whatever else is available. Public ambulatórios generally administer pills by packs of three, and pill users often return to find that the pill they have been using is no longer available. This renders whatever else is available interchangeable, by default, inverting the logic of choice into a logic of necessity, of sorts. In these public services, teenage girls are often proposed the injection in place of the pill, when it is available. One doctor I interviewed justified this as follows: "The injectable is much more effective. [...] That way, we know for sure the patient won't get pregnant and that we are not wasting resources."

Injectable contraceptives are pitched as a reliable alternative to the pill for young women, who are considered esquecidas (forgetful). In Salvador, much attention is given to the risky sexual practices of teenage girls leading to unwanted pregnancy (see Marinho et al. 2009). Although injections are barely represented in the available 2006 population-wide data on contraceptive use (Perpétuo and Wong 2009), I found that this was often the second or third most-delivered method in the public health posts in which I carried out observations. ${ }^{5}$

Oudshoorn's $(1996,1997)$ historical work on hormonal contraception provides a context to understand the dynamic of interchangeability that I am foregrounding here. She traces the gradual demise of the "One Size Fits All" approach to contraception promoted by early developers of the pill (Oudshoorn 1996). This led to the development of a "cafeteriamodel" of hormonal contraceptive diversity. ${ }^{6}$ In the late 1970 s, the WHO actively promoted research on long-acting hormonal contraceptives (hormonal injections and implants, in particular). These were seen as efficacious tools for population control programs because they are provider administered. This makes them good "technical delegates," that is, artifacts that are "designed to compensate for the perceived deficiencies of [their] users," such as women's tendencies to forget to take their pills daily (Oudshoorn 1997:44).

The WHO R\&D program stemmed from the recognition that "the" pill had only been taken up by "middle- and upper-class women in the western industrialized world" and not by women "in Southern countries" (Oudshoorn 1997:43). Injectable contraceptives such as Depo-Provera are described by the WHO team in a Science publication as "appropriate in developing countries but of relatively little interest in highly developed ones" (Crabbé et al. 1980). ${ }^{7}$ Technologies such as the pill contain a configured user (Oudshoorn 1996) that can inhibit its capacity to enter into new sociopolitical contexts.

For the pill to travel, it needed to be unpacked. Its circulation depended on making the object more fluid, so to speak (de Laet and Mol 2000). As new objects were produced from sex hormones, their circulation worked to differentiate between different consumer populations. This background is important for understanding how choices are presented in public family-planning institutions in Bahia. Low-income patients tend to be perceived as 
ignorant or inconsistent, and, although birth rates have decreased significantly in Brazil, relations between unbridled fertility, underdevelopment, and poverty continue to be commonly drawn in popular imaginaries.

Just as the pill and the injection are often rendered interchangeable, pills are readily swapped for each other. The work of choosing from the huge array of available pills is an exercise in differentiating between similar things. This work is heavily influenced by the active work of pharmaceutical representatives who strive to differentiate their products. One morning I sat with a gynecologist in a maternity unit in a small town near Salvador where private and public consultations were held back to back, in the same space. A young woman came in from the list of public-service patients. She discussed contraceptive options with the doctor, showing herself to be knowledgeable of different hormones and using the space to air queries about side effects. Although the young woman was not a paying patient, it was clear she did not want to be administered the standard pill available in the health post. She asked about the vaginal ring that she had heard about from her cousin and about the difference between the mini-pill and Ciclo21 (a popular Brazilian copy of Schering's Microvlar). They discussed Yasmin, "an excellent option," the doctor declared, but "very expensive." They settled on Levell and the doctor advised: "See how you get on with this. Take it every day at the same hour. And we'll explore until we find the right one for you."

The production of difference in such contexts is attendant on a prior notion of similarity that makes interchangeability possible. This notion of similarity is essentially analytical. Part of the ambiguity arises from the way contraceptive methods are classified. Most classifications blur use and mode of action. Contraceptive methods can be "barrier," "behavioral," "permanent," "emergency," or "long-acting reversible," and Brazilian categories until recently distinguished between "modern" and "traditional" methods. Popular categories tend to group methods according to their mode of administration rather than mode of action (thus differentiating between oral, injectable, or intra-uterine methods, across which hormonal methods are spread). While not everything is constructed as the same thing, and differences are produced between methods, my point is that the logic of interchangeability functions to smooth out differences between methods in the context of producing contraceptive choice. In the following section, I examine how ostensibly similar medicines may nevertheless be treated as radically different things, revealing how strategic the suspension of differences or the emphasis on similarity and interchangeability can be.

\section{Small Gaps, Big Differences}

Historian Watkins (2012) argues that there is nothing innovative about the purportedly new hormonal methods currently available on the market. Their sole novelty, she argues, resides in the marketing of the secondary, or lifestyle, effects of sex hormones. Watkins traces the tactics for "tinkering" with the pill's design, arguing that pharmaceutical companies promoted "distinctive aspects of what were essentially similar products" (2012:1465). The introduction of slight variation supplants genuine innovation with mere imitation (Watkins 2012:1465).

Interestingly, Watkins dwells less on the development of new modes of administration, concluding that the contraceptive options available to women today hardly differ from those available to their grandmothers (Watkins 2012:1464). This reveals how Watkins constructs the notion of similarity. Her notion of "hardly different" hinges on the similarity of the active principles themselves. She shows the extent to which sex hormone marketing hinges on demonstrating differences within non-contraceptive properties of "new" products. However, her analysis risks overlooking the way in which, in practice, marketing produces very different things. Small innovations produce big differences for users and prescribers alike. 
There is perhaps nothing new to the levonorgestrel compounds used in Norplant implants, the Mirena intra-uterine hormone-releasing system, or emergency contraceptive Plan B. However, these are so different in the minds of the women, doctors, and pharmacists I interviewed that they do not even enter a common category.

Yolanda is a tall, enthusiastic woman in her late twenties. We met one day in the waiting room of a private clinic, where a gynaecologist was running two hours late. Yolanda wears the characteristic smart office garb of pharmaceutical representatives and has a black attaché case full, I imagine, of amostras (free samples). She is a pharmaceutical representative for Nuvaring and is zealous about this "completely novel approach" to contraception. Nuvaring is a small silicon ring inserted in the vagina once a month. Yolanda explains to me that private practice doctors are enthusiastic about Nuvaring but have come up against "taboos" in prescribing this method.

Yolanda pulls a three-dimensional plastic model of the female reproductive organs out of her attaché case, explaining that she gives one to each doctor so they can educate their patients about the vagina, showing them how and where to insert Nuvaring. "Although we live in a very sexualized culture here in Brazil," she explains, "women don't know their own anatomy and have very traditional ideas still." Organon-Brasil actively works on this sexual trope in its marketing strategies. Yolanda enthusiastically recounts an event she recently held in a sex-shop for a group of female gynecologists. The objective, she explains, is for the gynecologist to become a purveyor of information about pleasure and sexuality and to have access to new ideas and information in this respect. ${ }^{8}$ The doctors she visits feel that their patients are not ready for this new approach to contraception. As one female gynecologist I interviewed explained:

Nuvaring is such a lovely method. But women have all sorts of preconceptions about it. That they will lose it in their vagina, or that their husbands will feel it. You have to explain that the vagina is a closed cavity, that Nuvaring can't be felt, and then you still have to get them to overcome their hang-ups about putting their hand in their vagina.

In the process of expanding contraceptive choices to patients, Nuvaring appears as something radically different for caregivers. This dispenser mechanism may have been experimented with for over 40 years and contain entirely un-innovative steroid compounds, but as it is taken up by users, this object arises as a markedly different thing. The logistics of its use (inserted for three weeks, removed, and then reinserted one week later) and the locale of application (the vagina) contribute to rendering the similar aspects (to the pill) almost negligible. Depending on the perspective adopted, this object appears as either just the same old thing in new garb (Watkins 2012) or as radically different. These differences may seem so considerable to end users that it causes them to lose sight altogether of the fact that they are using a hormonal contraceptive method. Many of the women who use the hormonereleasing Mirena intra-uterine device or hormonal implants opt for these methods precisely because they do not like the pill. While hormonal injections remain closely associated to and interchangeable with the pill, Mirena and implants have come to be perceived, by users, as unrelated to the pill.

Nara runs a small business and has been using Mirena for two years. She is 29 and has a four-year-old daughter who lives with her and her parents in a modern high-rise building. As a busy working mother, Nara appreciates not having to think about contraception daily. Her contraceptive history is marked by what she calls an "erratic" use of the pill. Her pregnancy was unplanned and, after an abortion three years later, she used a copper IUD. This gave her painful and heavy periods, and she became aware of having what she describes 
as "tremendous" premenstrual tension. Her gynecologist suggested Mirena-which is often prescribed in such cases - and her partner helped her meet the cost, which amounted to over US\$250. Nara explains that she never "got on" well with hormones, although Mirena has a hormonal delivery system and that she enjoys the fact that Mirena suppresses her period. When I press her on this she laughs, stating: "It's totally different." This can be explained by the fact that Nara adopted Mirena specifically as an alternative to the pill: "I went for it as an anticoncepcional (contraceptive), to be free to travel and everything without having to depend on a pill. And I got on well with it. And on top of everything, I stopped menstruating, then I was really loving it. I recommend it to everyone."

Likewise, Simone has been using hormonal implants for six years because she dislikes the pill. She is a professional photographer and runs a large events business. We met through mutual friends, and she and her husband, Carlos Eduardo (Cadu), humorously agreed to an interview because they were "in the middle of a family-planning crisis," debating whether or not to have a third child. Their first child was conceived while Simone was using the IUD, less than a year into their relationship. Simone adopted the implant after their second child because of its contraceptive reliability. Cadu - they both joked one evening over dinnerloved the implants because, they agreed, Simone was "infernal" when she menstruated. Simone who is vegan, a yogi, and makes use of a range of holistic therapies, such as Reiki, explains that she never uses medications and prefers to heal herself through meditation or by attending to the meaning that a particular physical ailment is conveying. She speaks of loving her implants in terms of a "confession," explaining that they give her tremendous "disposition" for life but that she worries "about what it might be doing to my organism. I love it, but I'm scared of using another one."

Simone recognizes the hormonal composition of her implants and its risks, and appreciates the effects of the testosterone that heightens her tesão (sexual desire) and gives her extra physical strength, but she clearly differentiates the implant from the pill - which she notes is more highly dosed-or the morning after pill that she describes as a "hormonal bomb." Beyond its practicality as a contraceptive, this method appears to Simone as less of a biomedical intervention in that she does not have to take a pill every day, a fact that sits more easily with her holistic vision of health. However, it enables her to sustain her demanding lifestyle and meet her professional and social obligations unencumbered by what she calls "emotional disruptions" or "menstrual fraqueza (weakness)."

How to account for the fact that so many hormonal implant and Mirena users I interviewed explicitly rejected any association between these and the pill? ${ }^{9}$ Modifications in the mode of administration induce changes in the perception and experience brought about by the object that may be so significant that they eclipse the common hormonal action between two drugs. To some extent, biomedical technologies such as Mirena or hormonal implants cease to appear as drugs, despite their pharmacological action. Marketing for Mirena somewhat downplays its hormonal action, drawing attention to the fact that it is an intrauterine device. It is therefore understandable that this method is less associated with its hormonal action. However, hormonal implants are widely appreciated for their menstrual suppressive action, and much of the promotion made of this method centers on controlling the hormonal fluxes associated with premenstrual tension. The implants are marketed as making possible a kind of hormonal enhancement that, according to some gynecologists, enables a form of sexual enhancement captured by the idiom of having disposição (disposition) by adducing exogenous testosterone or estrogen. ${ }^{10}$

Beyond facilitating use and overcoming forgetfulness, non-oral sex hormone repackaging strategies bear directly on the bioavailability of an active principle in the body. When a drug is swallowed and absorbed by the digestive system, it is metabolized by the liver. This reduces the bioavailability of the drug, requiring the administration of a higher 
dose. Alternative routes of administration avoid so-called first-pass effects through their delivery directly into the circulatory system. Differences of these kinds have important ramifications on the way an otherwise similar chemical compound acts in the body. Users' subjective experiences of a drug's efficacy are thus mediated by a range of factors that include its active principle, its mode of administration - which, in turn, determines the drug's pharmacokinetics - and the symbolic and social context within which it is prescribed and consumed.

Recent work in pharmaceutical anthropology (e.g., Schlosser and Ninnemann 2012) calls for the need to understand pharmaceutical efficacy in relation to the biological, sociological, and structural factors that shape individual responses to drugs. The cases discussed here reveal new fault lines through which the pharmakon exerts its influence, collapsing the distinctions between biological and sociological factors. The attention the industry places on pharmacodynamics suggests ways in which effects are both biological and social, symbolic and experienced in the flesh. In repeatedly alluding to differences in the effects of non-oral methods, these women are speaking at one and the same time of differences in the rates and magnitudes of pharmacologic responses, in the quotidian practices of use and in the medical encounters where these method are prescribed - as well as ensuing differences in the subjective identities locally conferred by "having an implant" or "using Mirena."

These cases reveal how different the same thing, repackaged, can look and feel. They point to what can be gained by considering pharmaceutical efficacy as the cumulative effect of the reputation, appearance, or subjective attachments to specific drugs, to their brands, pharmaceutical formulations, and modes of administration as well as to the social contexts within which drugs are used. The production of difference or the demonstration of similarity hinges on the enrollment of an intricate meshing of chemical, structural, economic, and semiotic elements. In this sense, the pharmaceutical effects I am underscoring here are prime examples of what Haraway (1991:200) calls "material-semiotic" nodes.

\section{Pharmaceutical Copies and Substitutions: Differentiating the Similar}

Given that roughly $75 \%$ of all hormonal contraceptives are obtained directly in pharmacies, often without prescription, these became privileged ethnographic sites. ${ }^{11}$ My observations in Bahian pharmacies allowed me to witness the practices of pharmaceutical substitution that commonly take place over the counter. Typically, clients arrive requesting a specific drug they have been prescribed or recommended or that they have failed to obtain in their local health post. It is common for the balconista (shop vendor) to answer that the drug is unavailable and add: "But we have the similar. It's the same thing." If the client is hesitant, the balconista may call attention to the similarity in the composition of the drug being offered, adding "and it's cheaper."

Similares often cost a fraction of the price of brand-name drugs. When clients inquire as to the significant price difference, balconistas may explain this by saying that brand-name drugs are imported while similares are "national products." Brand-name drugs have a certain prestige to them, like other imported goods. Imported goods such as grifes (designer goods), cosmetics, electro-domestic appliances, or electronics bring with them the social attributes of the elites who have access to them, so consuming them becomes a means of accessing elite status (Yaccoub 2011). Differences between imported brand-name drugs and similares are often presented by balconistas as one of packaging or origin, while the likeness between active principles is emphasized. Similares are usually promoted directly to pharmacies rather than to doctors. Several informants estimated that balconistas earn commissions of up to $50 \%$ on each box of similares they sell. This practice encourages balconistas to substitute brand- 
name medicines with similares. Given that Brazilians buy drugs out of pocket, the similar marketing strategy is extremely efficient and explains why more than half of drugs sold in Brazil are estimated to be similares. This has become a major sticking point, particularly as few pharmacies operate with a trained pharmacist. Although this was formerly illegal, pharmacy owners prefer paying fines to paying full-time pharmacists. In practice, in Bahia, pharmacists often "rent" their names to a pharmacy while working full-time jobs in laboratories (Kamat and Nichter [1998] relate a similar situation in India).

Despite recent efforts to levy fines more regularly, it is still rare to find a pharmacist behind the counter in Salvador. This is often seen as facilitating self-medication. ${ }^{12}$ During an interview, the president of Bahia's Pharmacy Council joked: "Even my own mother se receita (prescribes herself) and receita others in the family, so what can we do?" Almost anything is available without prescription in pharmacies (despite clear indications to the contrary on prescription drug packages), facilitating prescriptive forms of sociability, where people exchange information informally about the medicinal regimens they obtain directly, and often without prescription, in pharmacies.

Schering's regional representative, Anderson, a jovial and seductive father of two in his mid-thirties took me out on several occasions "to visit his gynecologists." The private practices in Anderson's clientele are luxurious, their interior design mixing white marble floors, spotless glass doors and colorful popular art. Each consultório has its own "look," and the predominantly female doctors wear pastel-colored lab coats with their first names embroidered in bright colors. Schering's products are considered muito chique (very chic), as one gynecologist put it.

On one occasion, Anderson and I ran into a group of representatives, identifiable by their matching black attaché cases. Vinicius, a representative from a Brazilian laboratory, approached me while Anderson was talking loudly on his flashy cell phone to ask me if I'm a rep too. He seems new to the scene and full of zeal. Anderson has snubbed him, but Vinicius tells me: "He's one of the best, his sales figures are unmatchable." When the gynecologist calls the reps in, we go in together, to save her time. Vinicius begins, nervous, mechanically reciting his pitch and laying down a large batch of amostras that the gynecologist silently slips into a drawer in her desk. "This guy is just a distribuidor de caixinhas (a pill pack distributor)," Anderson whispers to me, "his lab pushes quantity over quality of encounters." When it is his turn, Anderson engages in conversation with the doctor as an equal, taking his time, making a few jokes. He knows his products matter here. The doctor is more patient with him, his goods holding greater appeal. When the other reps have slipped out, thanking the doctor for her time, Anderson launches into his pitch for Yasmin. He is concerned because Libbs, a Brazilian similar laboratory, is launching a copy of Yasmin called Elaní.

Doctora, I want you to help me make Yasmin the number one option for your patients. It's the best product on the market: It's about your patient's well-being. She won't experience that swelling that makes her swap. And Yasmin is the real thing, the guarantee of quality, not just a copy.

Anderson exposes his scheme of exchanging Yasmin samples for receipts that ensures patients effectively get two boxes for the price of one and that he obtains a sale of Yasmin instead of seeing it swapped in the pharmacy for the similar. ${ }^{13}$ The doctor accepts, requesting a sample of the contraceptive injection Mesygyna for her empregada (domestic employee) who has just had an abortion. "I just can't do without her," she explains as she places the injection in her designer handbag. Doctors often pass on the free samples they receive to their kin or staff, a practice that pharmaceutical reps attempt to minimize to ensure each sample they deliver results in a sale. Anderson explains when we leave the consultório that 
laboratories source data from tertiary organizations to generate a sales potential indicator for each doctor he delivers amostras to. He jokes that as the market saturates his job has become that of a "sniper" as he has only one shot (or sample) to hit his sales target. For this reason, he is concerned about the substitutions that take place in pharmacies, undermining his painstaking work.

The substitution of reference drugs with similares is also common in public health services. When women express reluctance regarding the swapping of a pill for a different brand, doctors also employ the idiom of similarity to encourage skeptical patients to accept the proposed drug. Emphasis might be placed, as in the pharmacy, on the similitude of active principles and differences presented as merely ones of packaging or origin. What is interesting is that substitutions between reference drugs and their copies can work in both directions, so to speak, such as when the copy becomes a popular reference in itself. This is the case with the contraceptive pill Ciclo21, the Brazilian copy of Schering's Microvlar. It was revealed through an exchange I witnessed in an ambulatório on Salvador's periphery.

The only pill available there was Microvlar, a pill that was the subject of a national scandal after some 50 women declared that they had become pregnant while using it. A woman entered the consultation room and requested the renewal of her Ciclo21 prescription. The doctor took out three boxes of Microvlar, mechanically completing her file. The patient protested, asking why he was changing her pill. The doctor replied that they had not received Ciclo21. "However," he affirmed, "Microvlar is exactly the same thing, in a different box." Doubtful, the patient crossed her arms and said she did not get on well with Microvlar. Irritated, the doctor reiterated: "The only thing that's different is the box, querida (darling)! Are you going to eat the box, too?" Unflustered, the woman answered that she would prefer a prescription for Ciclo21. Attempting a more conciliatory tone, the doctor began reading out the "ingredients" on the box. "It's a shame, when you can get the exact same thing here for free," he lamented. Legally, similares - which are not considered interchangeable with reference drugs - should not be available in the SUS. However, the supply of drugs in the public sector obeys a law of bids (Lei de Licitações), which favors the laboratories that offer the lowest prices, generally similares.

These cases reveal some of the issues at play around the circulation of copies in the Brazilian pharmaceutical landscape. The market for copies has a complex internal dynamic, both where the difference between copy and original is concerned and between copies, which I now turn to. The substitution of brand-name drugs with similares or generics has unleashed a complex chain of regulatory practices around the copy. In Brazil, like elsewhere, the proliferation in types of copies arises out of questions concerning the quality of copies. As Hayden (2010:2) has argued, "the field of "the copy' [...] is crowded." In attending to the conceptual work that similarity does as it is transformed into a proper noun, Hayden opens up important questions about the differences that matter in claims to similarity.

Branding, in the field of the pharmaceutical copy, consists not in carving distinctions out of a field of equivalent products (Coombe 1998) but - to the contrary-in making likeness a mark of distinction (Hayden 2013). In the Mexican case that Hayden relates, similares are not a regulatory category but a successful brand of pharmacy that sells generic drugs. In Brazil, similares form a regulatory category and refer to copies that are equivalent to a reference drug in their chemical make-up (i.e., composed of the same active principles in equivalent concentration). They are, however, differentiated from generic drugs that are considered more equivalent and thereby "interchangeable" with a reference drug.

The category "generic" arose relatively late in Brazil and it was only in 1999, with the creation of ANVISA, that the distinction between similares and genericos was consolidated in regulatory terms. This distinction centers on the demonstration of both chemical equivalence and bioequivalence, that is, in terms of how the drug is metabolized by the body. 
Hayden refers to this distinction as one between pharmaceutical as effect rather than as substance (Hayden 2010:6). In practice, proving bioequivalence requires the realization of in vivo tests to measure how a copied compound acts in a living human body. Given that bioequivalence is a statistical measure that allows a variation of $20 \%$ between the bioavailability of a reference drug and its copy, the gold standard of qualitybioequivalence-effectively "means same enough" (Hayden 2010:7; emphasis in the original). ${ }^{14}$

Mauro, a consultant for a regional pharmacy chain who introduced me to several pharmacies, explained that brand-name drugs are promoted by representatives in doctors' practices, and similares are promoted in pharmacies, but that "nobody promotes generics, they're stuck on the pharmacy shelf, not actively represented." He works with a view of democratizing access to drugs and redeveloping the role of pharmacists beyond the "merely mercantile." As a public health-minded pharmacist and a member of the social movement, he downplays the difference between "researched" brand-name drugs and their copies, referring to the quality of nationally produced drugs in nationalist-inflected tones. Such ideas date back to the 1930s, when Vargas-Brazil's populist dictator and promoter of import substitution industrialization - declared that it was unpatriotic to use imported goods. By 1939, Brazilian pharmaceutical firms had integrated this into their marketing, drawing on the image of the "patriotic doctor" who prescribes national products that can "compete with and exceed foreign medicines" (Stücker and Cytrynowicz 2007). Mauro sees ANVISA's request to submit all copies to bioequivalence testing with a favorable eye, as this will reinforce the credibility of Brazilian firms.

ANVISA established in 2004 that all similar drugs must present tests to establish their bioequivalence with reference drugs to be (re)registered with the agency. The Brazilian pharmaceutical industry negotiated a 10-year interval to meet these requirements, which ends in 2014. Given the vast portion of the market occupied by similares, a revolution seems underway. ${ }^{15}$ What will happen to similares post-2014? Will they become generics or disappear? According to the Brazilian Law of Generics, a pharmacist can only substitute a brand-name drug with a generic. This raises an important question: If similares are submitted to the same tests as generics, will they become interchangeable with brand-name drugs? This is a grey area, as technically they will be, but legally it will not be possible unless the Law of Generics is modified. The main sticking point is the question of brand.

To be interchangeable, similares would need to be generics, and to be generics they would need to lose their brand, as generics are identified by their active principles and not by their name, unlike similares. Is this, Portilho (2012) asks, the end of the brand for similares? It appears that ANVISA will not legislate on this issue, leaving it as a strategic decision for each business to make. The brands of which generics are stripped produce relationships between consumers and commodities (Manning 2010; Nakassis 2013). Their trademarks are loaded with sociocultural meaning. Without active promotion or clear channels of consumer identification, generics are somewhat forsaken, as Mauro notes. Relationships between branded products and their consumers are the product of extensive efforts to build trust and consumer identification with products. as illustrated by the case of Microvlar's demise and Ciclo21 success.

The Brazilian laboratory EMS Sigma Farma's strategy is telling in this regard. In 2012, it launched a generic version of the oral contraceptive pill Yasmin, containing the fourth-generation hormone drospirenone. Yasmin is one of Brazil's leading brands, and is widely promoted for promoting bem-estar (well-being) by reducing swelling and weight gain due to the diuretic effects of the hormone drospirenone. Significantly, EMS simultaneously launched a new drospirenone-containing similar marketed as Dalyne, which is presented as a strategic competitor to Libbs's Elaní (introduced above), itself a copy of Yasmin. Is 
Dalyne - pharmaceutically speaking - the same as EMS's generic copy of Yasmin, but with a brand? EMS is capitalizing on the bioequivalence testing to produce both generics and a new form of copy: a branded bioequivalent copy. This indicates that ANVISA's call for all copies to be submitted to bioequivalence testing will not simply transform similares into generics. According to EMS (2013), Libbs currently holds half of the highly lucrative market for drospienone-ethinylestradiol contraceptives. EMS's strategy aims to capture Bayer's Yasmin clientele through legal substitutions by generics while encroaching on Libbs's market with the promotion of the branded version of its bioequivalent Yasmin copy Dalyne (which is cheaper than its generic Yasmin). EMS's market strategy is reflected in Dalyne's branding which promises more: "More beauty, more lightness and more freedom for more women."

What is striking about this case is that drospirenone is still-according to Bayerunder patent. In 2005, Libbs registered Elaní with ANVISA and was sued immediately by Schering (which has since been bought out by Bayer) for patent infringement. Libbs attacked on several fronts: It claimed that Schering's drospirenone patent number 1101055-0 relies on technology described in patent DE 3.022.337, registered in 1980 and is therefore in the public domain. After two Brazilian rulings denied Libbs's request to suspend Schering's patent, Libbs took the issue to the Brazilian Supreme Tribunal of Justice and to this day, Schering's patent has not been annulled, nor has Libbs been formally allowed or legally impeded from commercializing Elaní.

I attended a series of launch events for Elaní in Salvador and discussed the case with Arnaldo, Libbs's regional manager. He was confident that Elaní would go on the market as, in his words, it was more than just a copy. Unlike Yasmin, Elaní is marketed as an extendedregime pill, designed to reduce the annual number of periods, and sold in packs of 28 pills. According to Arnaldo, Libbs would win against Schering as "Elaní is not just a copy, it innovates too." These pharmaceutical maneuvers reveal the extent to which the market of the copy is subject to a process of segmentation. As the monopoly of brand-name drugs declines, lines of differentiation are drawn around the proliferation of emergent copies. The Brazilian pharmaceutical market is on the brink of a small revolution as similares are faded out and replaced by generics and a new pharmaceutical genre of branded bioequivalent copies. While EMS multiplies the sales opportunities for its bioequivalent Yasmin copies, Libbs's strategy is a form of imitative innovation that effectively repackages the copy. These strategies reveal the extent to which pharmaceutical marketing carefully negotiates the line between the production of something genuinely different (to protect intellectual property rights) and something completely identical—or, at the very least, bioequivalent.

\section{Conclusion}

Pharmaceutical sex hormones are peculiar objects. As chemical compounds that can be administered to prevent ovulation, suspend menstruation, "treat" menopause, certain cancers or premenstrual stress, improve skin condition, or assist in sex changes, they have farreaching implications for definitions of gender, familial relations, well-being, and national demographics. In giving an ethnographic account of hormonal contraceptive use and prescription practices in Brazil, this article examines how the control of variation is strategically employed by the pharmaceutical industry. This thick description of the dynamics at play in pharmaceutical development, marketing, and procurement highlights the ways in which these shape and respond to consumer choices across Brazil's two-tiered health system.

Given that the vast majority of hormonal drugs are procured directly in pharmacies, often without prescription, focusing solely on doctor-patient interactions in public services misses an important part of the picture. My aim has been to contribute to anthropological debates on pharmaceutical cultures as they relate to how drugs are made efficacious and to 
tensions surrounding the pharmaceutical copy (Greene 2011; Hayden 2007, 2010, 2013; Whyte et al. 2002).

The article considers how diversity is produced from ostensibly similar things through an analysis of the emergence of non-oral modes of administration for sex hormones. Differences between contraceptive medicines are at times strategically suspended by health practitioners in the context of emphasizing method interchangeability. In family-planning consultations where differences between pills or between pills and injectables are often bracketed together, patients may reasons resist this bracketing, as we saw with the case of the woman who contested the prescription of Microvlar, preferring Ciclo21. Conversely, differences between oral contraceptives and the sex hormones repacked in new delivery mechanisms may be highlighted, effacing the common hormonal mode of action between them. This accounts for Nara's statement that she does not do well with hormones, although she enjoys Mirena's menstrual suppressive effects. It also accounts for how Simone can opt for hormonal implants while explaining that she does not use medication and prefers to meditate or attend holistically to her health.

Regarding the production of copied drugs, the pharmaceutical industry carefully works to limit variation, striving to replicate an equivalent copy through reverse engineering. My focus here has thus been on the interplay between two types of differences: between modes of administration and between brand-name drugs and their copies. Although these usually belong to different conversations, I examine them together to reveal the combined effects of modulations in dosages, "original" and "copied" active principles, modes of administration, and branding, which together produce the pharmaceutical efficacies that doctors, patients, and pharmacists navigate.

The specificity of steroid hormones, in relation to other pharmaceutical classes, is that users acquire them in a multitude of different galenic formulations, packaging, color, or name, each prescribed with slightly different indications or marketed to different patient profiles. Such variations, I have argued, have far reaching implications for the way in which the object is perceived, experienced and understood to be efficacious. "How can pills with similar contents look so different and pills with different contents look so similar?" Greene (2011:120) asks. "The brand of a drug does not stop at the name or logo. Rather, the brand extends into the pill itself, in the form of its particular contour, bevel, engraving, or colour" (Greene 2011:120).

Much of the existing work on the pharmaceutical copy has attended to intellectual property issues concerning the active principles and much less to how modes of administration or the materializations of brand that Greene outlines combine with these-a gap I attempt to fill here. The way hormonal contraceptives are experienced depends on a subtle balance of tangible and intangible elements that include, beyond the chemical composition of a drug, its design, name and, increasingly, its trademarked concept (e.g., FewerPeriods. MorePossibilities. ${ }^{\mathrm{TM}}$ for the Seasonale extended-regime pill). The concept that a brand carries, such as "well-being" or "weight-loss" that marketing has associated with Yasmin in Brazil, seeps into the hormonal substance itself, drospirenone, in this case. Thus, aspects of the branding process may percolate unevenly to the copies of the chemical compounds as these are remade by generic or similar laboratories.

The generic stands at the antipode of branding processes. So much so that trademarks are at risk of a cruel form of irony if they are too successful and turn into nouns or verbs, a process known as genericide. Legal regimes strive to separate trademarks and brands from the product, as when the brand and the thing merge the specificity of the brand is lost in the generic form. Pharmaceutical maneuvers around the generic must navigate a fine line, retaining something of the identity of the original, which, as we have seen, goes beyond its pharmacological composition. The immanent reclassification of similares in Brazil as either 
certified generics or branded bioequivalent copies signals that generic drugs are gaining new competitors on the side of the copy. What difference does the oxymoron "branded-generic" make to the field the generic? Is this the "defeat of the generic revolution"-and its promise of delivering cheap and effective drugs to all—as one public health-minded pharmacist I met would have it?

\section{Notes}

Acknowledgments. During my visits to Salvador, I was immensely lucky to benefit from the intellectual stimulation and the friendship of the researchers at MUSA, Instituto de Saúde Coletiva, in particular Estela Aquino, Cecilia McCallum, Ana Paulo dos Reis, and Greice Menezes. Mauro Bitencourt deserves special thanks for his guidance, as do the women who shared their stories or tolerated my presence during their consultations. I am grateful to Maurice Cassier, Alice Desclaux, Cori Hayden, Ilana Lowy, Jean-Paul Gaudillière, and to the three anonymous MAQ reviewers for their excellent critiques and suggestions on earlier versions of this article.

1. Although this percentage has remained stable, the population has expanded from 70 million in 1960 to 191 million in 2008.

2. In $2006,20.5 \%$ of women with at least eight years of schooling relied on sterilization, compared to $65.5 \%$ of women with no formal education (Perpétuo \& Wong 2009:93-94).

3 . The doctors who allowed me to observe consultations usually engaged with me as well as with the medical students who were often present.

4. My interest in the question of pharmaceutical copies brought forth extensive descriptions of the market dynamics at stake, from the perspective of those promoting them.

5. This is supported by Perpétuo and Wong's analysis, who state: "For women without any formal education, injectable contraceptives were the second choice, a little above female sterilization" (2009:100, my translation).

6. It found its rationale in the limited uptake of the pill worldwide a fact accounted for by reference to the heterogeneity of women's personal, cultural, and religious circumstances.

7. Depo-Provera has a troubling history, worldwide. In the United States, it was repeatedly denied FDA approval until 1992. Women's health organizations worldwide have opposed Depo-Provera, highlighting its potential for abuse and adverse health effects.

8. In his ethnography of pharmaceutical sales practices, former-salesperson-turnedanthropologist Oldani (2004) remarks on the importance of strategic gifting in pharmaceutical marketing. This gift economy, into which pharmaceutical corporations invest billions of dollars, serves to craft relations with doctors and gage promotional strategies as well as generate sales.

9. This fact is not unanimous. Some women, particularly those troubled by swelling and weight gain, made a clear relation between the hormonal composition of oral and non-oral steroid contraceptives.

10. In Brazil, most implant users obtain these through private gynecologists who source them via compounding pharmacies. Hormonal implants are presented as individually tailored to a patient's hormonal profile. For details on compounding pharmacies, see Sanabria (2010b).

11. For a detailed ethnographic analysis of the operation of pharmacies in India, where most drugs are also available over the counter, see Kamat and Nichter 1998.

12. For an important critique of the routine use of the term "self-medication" see Das and Das (2006).

13. This is an example of what Oldani (2004) refers to as a "novel [pharmaceutical] gift cycle." 
14. This margin may be significant for active principles that have narrow therapeutic indexes, such as ARVs or hormonal contraceptives. For these drugs, minute variations that remain within the margin allowed by bioequivalence testing may have significant clinical effects (Rumel et al. 2006).

15. According to the Federal Council of Pharmacy, 18,000 drug prescriptions exist in Brazil, $70 \%$ of which are similares, the remaining $30 \%$ being either brand-name or generic drugs. See http://www.cff.org.br/sistemas/geral/revista/pdf/78/10-anvisa.pdf (accessed March 21, 2013).

\section{References Cited}

Cassier, M., and M. Corrêa

2009 Éloge de la copie: Le reverse-engineering des antirétroviraux dans les laboratoires pharmaceutiques brésiliens. Sciences Sociales \& Santé 27:77-104.

Coombe, $\mathrm{R}$.

1998 The Cultural Life of Intellectual Properties. Durham: Duke University Press.

Corrêa, $\mathrm{M}$.

2001 Novas technologias reprodutivas: Limites da biologia ou biologia sem limites? Rio de Janeiro: Editora da UERJ.

Crabbé, P., E. Diczfalusy, and C. Djerassi

1980 Injectable Contraceptive Synthesis: An Example of International Cooperation.

Science 209:992-994.

Das, V., and R. Das

2006 Pharmaceuticals in Urban Ecologies: The Register of the Local. In Global

Pharmaceuticals: Ethics, Markets, Practices. A. Petryna, A. Lakoff, and A. Kleinman, eds. Pp. 171-205. Durham: Duke University Press.

de Laet, M., and A. Mol

2000 The Zimbabwe Bush Pump: Mechanics of a Fluid Technology. Social Studies of Science 30:225-263.

EMS Sigma Pharma

2013 Sigma em ação. Linha Clínica. Prospective Report. 53 pp.

Greene, J.

2011 The Substance of the Brand. The Lancet 378:120-121.

Haraway, D.

1991 Simians, Cyborgs, and Women: The Reinvention of Nature. London: Free Association Books.

Hartmann, B.

1995 Reproductive Rights and Wrongs: The Global Politics of Population Control. Revised ed. Cambridge: South End Press.

Hayden, C.

2007 A Generic Solution? Pharmaceuticals and the Politics of the Similar in Mexico. Current Anthropology 48:475-495.

2010 New Same Things. Paper given at the History and Theory Working Group, University of Toronto, October 6, 2010.

2013 Distinctively Similar: A Generic Problem. UC Davis Law Review 47:601-632.

IMS Institute for Healthcare Informatics

2011 The Global Use of Medicines: Outlook through 2015. IMS Health Incorporated. http://www.imshealth.com/deployedfiles/ims/Global/Content/Insights/IMS\%20Institute $\% 20$ for\%20Healthcare\%20Informatics/Global_Use_of_Medicines_Report.pdf (accessed June 20, 2014). 
Kamat, V., and M. Nichter

1998 Pharmacies, Self-medication and Pharmaceutical Marketing in Bombay, India. Social

Science \& Medicine 47:779-794.

Krause, E., and S. DeZordo

2012 Introduction. Ethnography and Biopolitics: Tracing "Rationalities" of Reproduction across the North-South Divide. Anthropology \& Medicine 19:137-151.

Loyola, M. A.

2010 Cinquenta anos de anticoncepção hormonal: A mulher e a pílula. ComCiência. http://www.comciencia.br/comciencia/handler.php?section $=8 \&$ edicao $=57 \& \mathrm{id}=717$

(accessed June 20, 2014).

Manning, $\mathrm{P}$.

2010 Semiotics of Brand. Annual Review of Anthropology 39:33-49.

Marinho, L., E. Aquino, and C. Almeida

2009 Contraceptive Practices and Sexual Initiation among Young People in Brazil. Cadernos de Saúde Pública 25:S227-S239.

Mol, A.

2002 The Body Multiple: Ontology in Medical Practice. Durham: Duke University Press.

Nakassis, C.

2013 Brands and Their Surfeits. Cultural Anthropology 28:111-126.

Oldani, M.

2004 Thick Prescriptions: Toward an Interpretation of Pharmaceutical Sales Practices. Medical Anthropology Quarterly 18:325-356.

Oudshoorn, N.

1996 The Decline of the One-size-fits-all Paradigm, or, How Reproductive Scientists Try to

Cope with Postmodernity. In Between Monsters, Goddesses \& Cyborgs: Feminist

Confrontations with Science, Medicine and Cyberspace. N. Lykke and R. Braidotti, eds.

Pp. 154-169. London: Zed Books.

1997 From Population Control Politics to Chemicals: The WHO as an Intermediary

Organization in Contraceptive Development. Social Studies of Science 27:41-72.

Pedro, J. M.

2003 A experiência com contraceptivos no Brasil: Uma questão de geração. Revista

Brasileira de História 23:239-260.

Perpétuo, I., and L. Wong

2009 Desigualdade socioeconômica na utilização de métodos anticoncepcionais no Brasil.

In Pesquisa nacional de demografia e saúde: Dimensões do processo reprodutivo e da

saúde da criança. Ministério da Saúde. Pp. 87-104. DF: Centro Brasileiro de Análise e Planejamento.

Petryna, A.

2009 When Experiments Travel: Clinical Trials and the Global Search for Human Subjects.

Princeton: Princeton University Press.

Portilho, D.

2012 Marcas dos medicamentos similares e 2014. Valor Econômico. http://www.valor.com.br/brasil/2711146/marcas-dos-medicamentos-similares-e-

2014\#ixzz1xgYmPKaM (accessed March 22, /2013).

Rumel, D., S. Nishioka, and A. A. Marçal dos Santos

2006 Intercambialidade de medicamentos: Abordagem clínica e o ponto de vista do consumidor. Revista Saúde Pública 40:921-927.

Sanabria, E.

2010a From Sub- to Super-citizenship: Sex Hormones and the Body Politic in Brazil. Ethnos. 75:377-401. 
2010b Le médicament, un objet évanescent: Essai sur la fabrication et la consommation des substances pharmaceutiques. Techniques \& culture 52-53:168-189.

Stücker, A., and M. M. Cyrtrynowicz

2007 Origens e trajetória da indústria farmacêutica no Brasil. São Paulo: Narrativa Um.

Schlosser, A., and K. Ninnemann

2012 Introduction: The Anthropology of Psychopharmaceuticals: Cultural and Pharmacological Efficacies in Context. Culture Medicine and Psychiatry 36:2-9.

Thuot, A., M. Georgecu, C. Bensemmane, C. Koopmans, and H. Bezerra

2012 Brazil Pharma Report. Focus Reports. February 2012.

http://issuu.com/focusreports/docs/phex_brazil_2012 (accessed January 15, 2013).

Watkins, E.

2012 How the Pill Became a Lifestyle Drug: The Pharmaceutical Industry and Birth Control in the United States since 1960. American Journal of Public Health 102:14621472.

Whyte, S. R., S. van der Geest, and A. Hardon

2002 Social Lives of Medicines. Cambridge: Cambridge University Press.

Yaccoub, $\mathrm{H}$.

2011 A chamada "nova classe média." Cultura material, inclusão e distinção social in Horizontes Antropológicos 36:197-231. 